\title{
Effect of Chloride Ions Concentrations to Breakdown the Passive Film on Rebar Surface Exposed to L-Arginine Containing Pore Solution
}

\author{
Jitendra Kumar Singh ${ }^{1,+}\left(\mathbb{D}\right.$, Soumen Mandal ${ }^{2,+}$, , Han-Seung Lee ${ }^{3, *}$ and Hyun-Min Yang ${ }^{1, *}$ \\ 1 Innovative Durable Building and Infrastructure Research Center, Hanyang University, 55 Hanyangdaehak-ro, \\ Sangrok-gu, Gyeonggi-do, Ansan-si 15588, Korea; jk200386@hanyang.ac.kr \\ 2 Intelligent Construction Automation Center, Kyungpook National University, 80, Daehak-ro, Buk-gu, \\ Daegu 41566, Korea; sou.chm@gmail.com \\ 3 Department of Architectural Engineering, Hanyang University, 55 Hanyangdaehak-ro, Sangrok-gu, \\ Gyeonggi-do, Ansan-si 15588, Korea \\ * Correspondence: ercleehs@hanyang.ac.kr (H.-S.L.); yhm04@hanyang.ac.kr (H.-M.Y.); \\ Tel.: +82-31-436-8159 (H.-S.L.); Fax: +82-31-436-8169 (H.-S.L.) \\ + Equal authors contribution.
}

check for updates

Citation: Singh, J.K.; Mandal, S.; Lee, H.-S.; Yang, H.-M. Effect of Chloride Ions Concentrations to Breakdown the Passive Film on Rebar Surface Exposed to L-Arginine Containing Pore Solution. Materials 2021, 14, 5693. https://doi.org/10.3390/ma14195693

Academic Editor: Bożena Łosiewicz

Received: 4 August 2021

Accepted: 28 September 2021

Published: 30 September 2021

Publisher's Note: MDPI stays neutral with regard to jurisdictional claims in published maps and institutional affiliations.

Copyright: (c) 2021 by the authors. Licensee MDPI, Basel, Switzerland. This article is an open access article distributed under the terms and conditions of the Creative Commons Attribution (CC BY) license (https:/ / creativecommons.org/licenses/by/ $4.0 /)$.
Abstract: In the present study, 0.115 M L-arginine (LA) has been used as an eco-friendly inhibitor in simulated concrete pore solutions (SP-0) in order to form passive films on a steel rebar-solution interface until $144 \mathrm{~h}$. Hence, 0.51 (SP-1) and $0.85 \mathrm{M} \mathrm{NaCl}$ (SP-2) were added in LA containing SP-0 solution to breakdown the passive film and to initiate corrosion reactions. The electrochemical results show that the charge transfer resistance $\left(R_{c t}\right)$ of steel rebar exposed to SP-1 and SP-2 solutions increased with respect to immersion periods. The sample exposed to the SP-2 solution initiated the corrosion reaction at the steel rebar-solution interface after $24 \mathrm{~h}$ of $\mathrm{NaCl}$ addition and formed pits; on the other hand, the sample without $\mathrm{NaCl}$ added, i.e., SP-0, showed agglomeration and dense morphology of corrosion products.

Keywords: steel rebar; concrete pore solution; passive film; corrosion; electrochemical impedance spectroscopy; scanning electron microscopy

\section{Introduction}

Premature distress of reinforced concrete $(\mathrm{RC})$ results from poor workmanship, lack of maintenance, atmospheric effects, and the ingress of chloride ion $\left(\mathrm{Cl}^{-}\right)$into concrete. Moreover, $\mathrm{Cl}^{-}$ions are the most affecting factor for the distress of $\mathrm{RC}$ structures [1]. This ion perturbs passive oxide films, which formed onto the embedded rebar in RC and accelerated deterioration via the formation of intermediate corrosion products. Most of the bridges located in coastal areas or those immersed in sea water are prone to corrosion. In this case, $\mathrm{Cl}^{-}$ions act as catalysts to enhance corrosion reactions of embedded rebar [2]. Therefore, inhibitors are used as alternatives for delaying the onset of corrosion due to their unequivocal advantages, i.e., they are convenient, inexpensive, available, and highly corrosion resistant. It was proven that nitrite based inhibitors are very effective for combating the corrosion of steel rebar, however, it has been debarred owing to its carcinogenicity and toxicity [3].

There are many controversies regarding the threshold values of chloride ions for de-passivation or the initiation of steel rebar corrosion exposed to concrete, mortar, and pore solution conditions. Alonso et al. [4] have explained that there is no unique or fixed value of chloride threshold for active corrosion of steel rebar embedded in concrete because it depends on several factors such as water/cement ratio, relative humidity, temperature, blended materials, concrete mix proportions, cement type, tricalcium aluminate content in cement, steel chemistry and surface conditions, source of chloride, and types 
of inhibitors [4]. However, Hausmann and Gouda have determined that the ratio of 0.6 $\left[\mathrm{Cl}^{-}\right] /\left[\mathrm{OH}^{-}\right]$is the chloride threshold for steel rebars immersed in pore solutions $[5,6]$. Vassie has derived the chloride threshold value of bridges in UK, and it numberd from 0.2 to $1.5 \%$ by weight of the cement [7]. Moreover, the British standard limit for chloride threshold measures up to $0.1 \%$ for pre-stressed concrete and less than $0.4 \%$ for the RC structures [8]. The acceptable ranges of chloride threshold value are from 0.2 to $0.4 \%$ by weight of the cement used to predict the corrosion-free life of a concrete structure [9-13]. The chloride threshold value can be increased if the $\mathrm{pH}$ of a concrete pore solution increased and is attributed to an increase in hydroxyl ion [14,15]. The chloride threshold values can be deterred based on the types of salt present in the service conditions of the concrete [16].

$\mathrm{Xu}$ et al. [17] have determined the chloride threshold values of calcium nitrite $\left(\mathrm{Ca}\left(\mathrm{NO}_{2}\right)_{2}\right)$, zinc oxide ( $\mathrm{ZnO}$ ), and $N, N^{\prime}$-dimethylaminoethanol (DMEA) inhibitors in saturated calcium hydroxide solution, and they have found that inhibitors had a marginal effect on increasing the chloride threshold value [17]. The amino acid based corrosion inhibitor, i.e., aspartate, has increased the threshold chloride content by adsorbing onto the steel surface [18]. The aspartate has chelating characteristics; therefore, it shows inhibitive properties through a negative charge repulsion by a non-adsorbed carboxylate group. Two percent ginger extract has improved the chloride threshold values of steel rebar from $0.02 \mathrm{~mol} / \mathrm{L}$ to $0.08 \mathrm{~mol} / \mathrm{L}$ in simulated concrete pore solutions by forming a carbonaceous organic film, which retards cathodic and anodic reactions [19]. The chloride threshold value of $N, N^{\prime}-$ dimethylaminoethanol inhibitor has been found to be $0.4\left[\mathrm{Cl}^{-}\right] /\left[\mathrm{OH}^{-}\right]$, which can be increased by increasing the concentration of inhibitor [20]. Nihali et al. [21] have studied the effect of $\mathrm{Na}_{3} \mathrm{PO}_{4}$ inhibitor on the chloride threshold in saturated $\mathrm{Ca}(\mathrm{OH})_{2}$ solutions, and they have found that, once the inhibitor was added, the chloride threshold value increased from 0.6 to 1.5 and is attributed to the formation of iron phosphate $\mathrm{Fe}_{3}\left(\mathrm{PO}_{4}\right)_{2} \cdot 8 \mathrm{H}_{2} \mathrm{O}$ as passive films [21].

There are many eco-friendly corrosion inhibitors for the mitigation of steel corrosion in acidic conditions, i.e., $\mathrm{HCl}$ and $\mathrm{H}_{2} \mathrm{SO}_{4}$ [22-24], but they are scarcely available on the steel rebar corrosion embedded in concrete or exposed to simulated concrete conditions added with $\mathrm{NaCl}$. The chloride threshold of some nitrite-based inhibitor has been studied, and such types of inhibitor are hazardous; therefore, they have been banned by USA and European countries [3]. However, there is little effort made by the researchers with respect to investigating the chloride threshold of eco-friendly corrosion inhibitors $[25,26]$. While we have described the effect of some eco-friendly inhibitors with respect to retarding steel rebar corrosion in the aforementioned paragraphs, none of the literature investigated or explained the chloride threshold of L-arginine (LA) containing inhibitors with exposure periods in simulated concrete pore (SP) solutions. In our earlier studies, we have found that $0.115 \mathrm{M}$ LA exhibited $96 \%$ corrosion inhibition efficiency in $0.17 \mathrm{M} \mathrm{NaCl}$ added simulated concrete pore solutions [27]. Therefore, in the present study, we have selected $0.115 \mathrm{M} \mathrm{LA}$ for chloride threshold determination. We have kept a steel rebar in SP + 0.115 M LA for $144 \mathrm{~h}$ at different concentrations, i.e., a certain amount of $\mathrm{NaCl}$ from 0.51 to $0.85 \mathrm{M}$ has been added into the solution to breakdown the passive film and initiate the corrosion reaction. Different electrochemical studies have been performed up to $168 \mathrm{~h}$ after the addition of $\mathrm{NaCl}$. The characterizations of passive/oxide films formed onto the steel rebar are studied by scanning electron microscopy (SEM) after 168 of exposure in SP + 0.115 M LA (SP-0), SP $+0.115 \mathrm{M} \mathrm{LA}+0.51 \mathrm{M} \mathrm{NaCl}$ (SP-1), and SP + 0.115 M LA + 0.85 M NaCl (SP-2) solutions.

\section{Materials and Methods}

\subsection{Materials}

In the present study, a $16 \mathrm{~mm}$ diameter and $10 \mathrm{~mm}$ thick plain carbon steel rebar possessing chemical compositions shown in Table 1 was determined by X-ray fluorescence (XRF, Rigaku, Tokyo, Japan). The steel rebars were polished with emery paper measuring 220 to 2000 in size. It is important to induce a mirror finished surface on the steel rebar; therefore, they were polished with alumina slurry $(0.5 \mu \mathrm{m}$ particle size $)$. These steel 
rebars were used for electrochemical studies as well as other characterizations to assess reproducibility and to obtain an average result.

Table 1. Chemical composition of steel rebar.

\begin{tabular}{ccccccccccc}
\hline \multicolumn{10}{c}{ Elements (wt.\%) } \\
\hline Fe & Mn & Si & C & Cr & Ni & Cu & P & Mo & S & Sn \\
\hline 98.501 & 0.90 & 0.25 & 0.235 & 0.037 & 0.028 & 0.018 & 0.014 & 0.009 & 0.006 & 0.002 \\
\hline
\end{tabular}

The electrochemical studies were carried out in simulated concrete pore (SP) solutions. The chemical composition for the synthesis of this solution was described in our earlier published work [28-30] and others [31,32] where $\mathrm{NaOH}, \mathrm{KOH}$, and $\mathrm{CaO}$ were used. In this solution, $\mathrm{SP}$ was filtered with Whatman paper where insoluble $\mathrm{CaO}$ was removed. The amount of 0.115 M L-arginine (LA, purchased from Sigma-Aldrich, Seoul, Korea) was dissolved in the SP solution. The details about LA can be found elsewhere [27,33]. The passivation of steel rebars was performed by keeping them in SP + 0.115 M LA solution for $144 \mathrm{~h}$. After that, different amounts of $\mathrm{NaCl}$ were added to determine the chloride threshold of the passive film. The details of the solution composition are shown in Table 2.

Table 2. Details of solution used in present study.

\begin{tabular}{ccc}
\hline Sl. No. & Solution & Sample ID \\
\hline 1. & SP $+0.115 \mathrm{M} \mathrm{LA}$ & SP-0 \\
2. & $\mathrm{SP}+0.115 \mathrm{M} \mathrm{LA}+0.51 \mathrm{M} \mathrm{NaCl}$ & SP-1 \\
3. & $\mathrm{SP}+0.115 \mathrm{M} \mathrm{LA}+0.85 \mathrm{M} \mathrm{NaCl}$ & SP-2 \\
\hline
\end{tabular}

\subsection{Electrochemical Studies}

Electrochemical studies of steel rebars were performed on a $0.78 \mathrm{~cm}^{2}$ polished surface. Initially, the rebar samples were kept in SP + $0.115 \mathrm{M}$ LA solution, i.e., SP-0 was kept for $144 \mathrm{~h}$ to ensure that a uniform passive film has been formed. Thereafter, different amounts, i.e., $0.51 \mathrm{M}$ and $0.85 \mathrm{M} \mathrm{NaCl}$, were added to the solutions in order to breakdown the passive film and to determine the chloride threshold. The samples were kept in the solution for $30 \mathrm{~min}$ to achieve a stabilized open circuit potential (OCP) prior to start the electrochemical impedance spectroscopy (EIS) studies. EIS was performed by three electrode systems where the steel rebar functioned as the working electrode (WE), saturated calomel electrode (SCE), and reference electrode (RE) and platinum wire functioned as the counter electrode (CE).

The assessment for the nucleation, growth, and breakdown of passive film formed at steel rebar-solution interface was carried out by EIS using Potentiostat (VersaSTAT (Princeton applied Research, Oak Ridge, TN, USA)). A $10 \mathrm{mV}$ amplitude of sinusoidal voltage varying its frequencies between $100 \mathrm{kHz}$ and $10 \mathrm{mHz}$ was imposed on the exposed surface of the steel rebars at their OCP. Three steel rebar samples were exposed in the solutions, and EIS tests were performed for all the samples. The mean values of the raw data were computed and are shown in the manuscript.

\subsection{Analysis of the Passive Film and Corrosion Products}

After $168 \mathrm{~h}$ of exposure in different solutions, the morphology of the passive film/corrosion products was examined by energy dispersive $\mathrm{X}$-ray (EDS) analysis that was complementarily available to scanning electron microscopy (SEM, MIRA3, TESCAN, Brno, Czech Republic) at $15 \mathrm{kV}$. The steel surface was rinsed with distilled water prior to taking the SEM images to ascertain the removal of deposit salts. The other details about characterization techniques are described in our earlier published papers $[29,30]$. 


\section{Results and Discussion}

\subsection{Electrochemical Studies}

\subsubsection{Measurement of Open Circuit Potential (OCP)}

The OCP measurement results are shown in Figure 1. The OCP of the passivated steel rebar stabilized by adsorbing the LA at the surface, which formed the $\mathrm{Fe}$-Zwitterion complex that protects rebar from corrosion [34]. However, once $0.51 \mathrm{M} \mathrm{NaCl}$ was added, i.e., $\mathrm{SP}-1$, the $\mathrm{OCP}$ was found to be active compared to $\mathrm{SP}-0$, and it is gradually decreased after $48 \mathrm{~h}$ of $\mathrm{NaCl}$ addition. As the amount of $\mathrm{NaCl}$ increased, i.e., SP-2, the OCP became more negative (active) compared to SP- 0 and SP- 1 , and this is attributed to the breakdown of the passive layer. It is found that up to $0.85 \mathrm{M} \mathrm{NaCl}$, i.e., SP-2, there is no risk of steel rebar corrosion during $1 \mathrm{~h}$ of addition because the OCP of this sample is higher at $-520 \mathrm{mV}$ vs. SCE. It is suggested by other researchers that if the OCP of steel rebar is falls down to $-520 \mathrm{mV}$ vs. SCE, then it is considered as a risk of corrosion when exposed to chloride containing solutions $[16,20,35-37]$. It can be observed from Figure 1 that as the immersion durations were extended up to $24 \mathrm{~h}$, the OCP of steel rebar immersed in SP-2 solution shifted towards the active direction and was lower than $-520 \mathrm{mV}$ vs. SCE. Thus, it can be suggested that the chloride threshold of steel rebar exposed to SP + 0.115 M LA solution after $24 \mathrm{~h}$ of exposure is $0.85 \mathrm{M} \mathrm{NaCl}$. Moreover, the OCP results of the steel rebar immersed in SP-1 solution up to $168 \mathrm{~h}$ of exposure suggest that there is no risk of corrosion. The OCPs of steel rebars exposed to $\mathrm{NaCl}$ added solutions, i.e., SP-1 and SP-2, stabilized after $72 \mathrm{~h}$, which is attributed to the complex reaction where $\mathrm{Cl}^{-}$ions form $\mathrm{Cl}-(Z$ witterion)-Fe complex. The LA is fixed in the present study; thus, it required a fixed amount of $\mathrm{NaCl}$ to form the $\mathrm{Cl}$-(Zwitterion)-Fe complex, which adsorbed onto the rebar surface. However, once the $\mathrm{NaCl}$ amount increased beyond the optimum amount of $\mathrm{LA}$, the $\mathrm{Cl}^{-}$ions locally attacked and initiated corrosion reactions at the surface of the steel rebar. Thus, a lower $\mathrm{OCP}$ was found at extended periods of exposure.

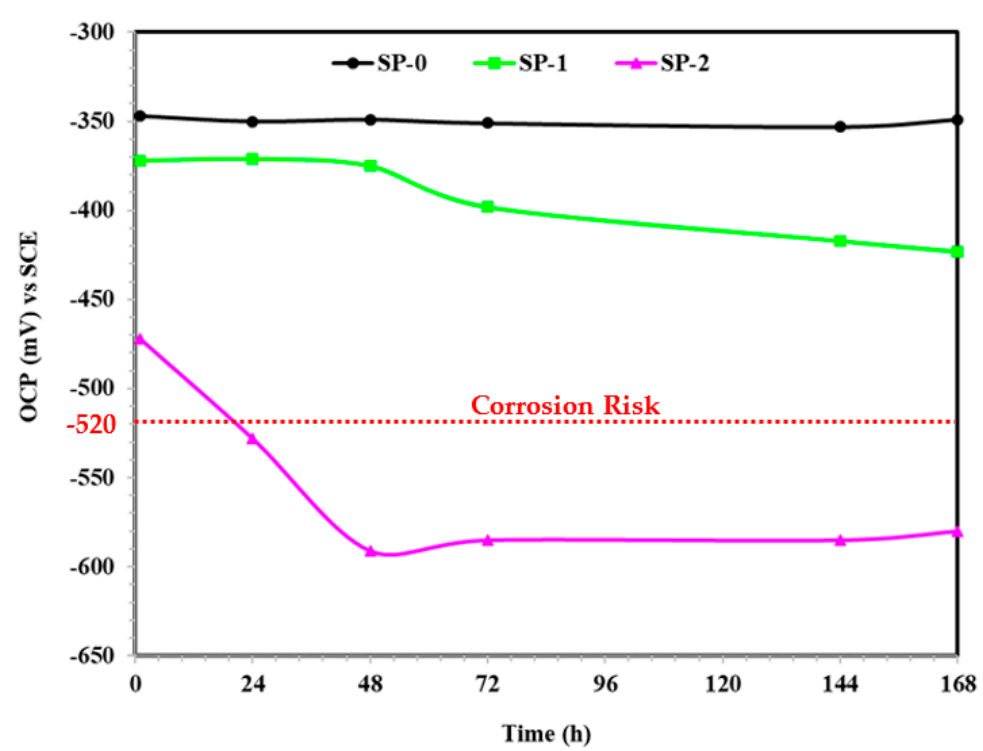

Figure 1. OCP measurement with immersion time.

\subsubsection{EIS with Time}

The Nyquist plots of steel rebars with exposure periods are shown in Figures 2-4. The Nyquist plots of steel rebar after $1 \mathrm{~h}$ of exposure to the SP-0 solution exhibited the highest magnitude (Figure 2a), revealing the formation of adherent and stable film. This film might consist of a Zwitterion-Fe complex. On the contrary, once $\mathrm{NaCl}$ was added, there was a significant reduction in magnitude of Nyquist plots (Figure 2a) due to the attack of $\mathrm{Cl}^{-}$ ions on the passive film, i.e., Zwitterion-Fe complex [20]. This result correlates with OCP 
plots where the OCP difference of steel rebar was more than $120 \mathrm{mV}$ vs. SCE between SP-0 and SP-2.
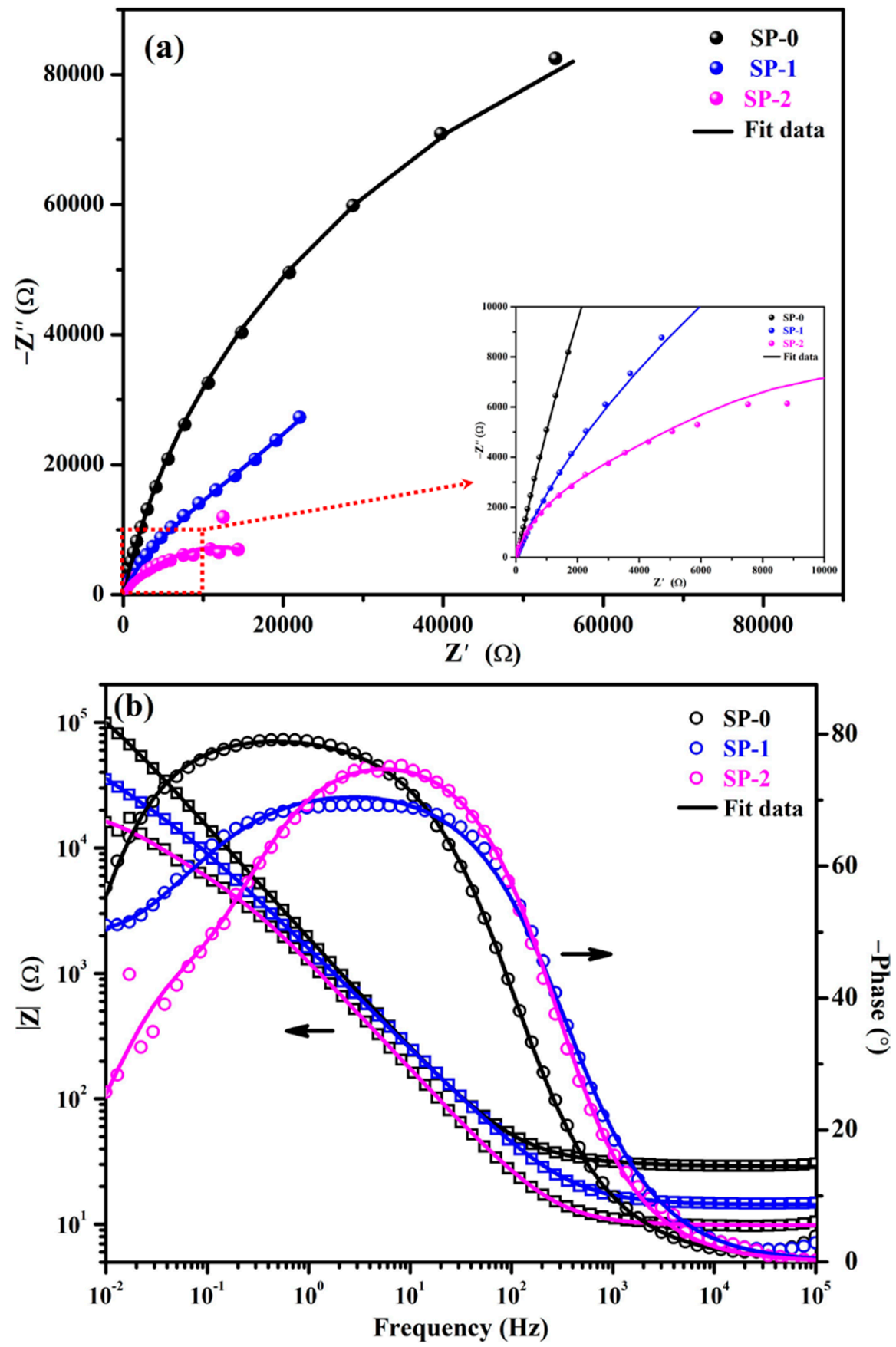

Figure 2. EIS plots for (a) Nyquist and (b) Bode after $1 \mathrm{~h}$ of immersion.

The modulus Bode plots of steel rebars after $1 \mathrm{~h}$ of immersion are illustrated in Figure $2 \mathrm{~b}$. The total impedance of steel rebar immersed in the SP-0 solution measured the highest at $0.01 \mathrm{~Hz}$ followed by SP- 1 and SP-2. The impedance values of $\mathrm{NaCl}$ added solution decreased gradually once the amount increased, suggesting that the formed passive film or adsorbed Zwitterion-Fe complex started to perturb. It is well known that once the chloride concentration increased, the deterioration of passive film increased [17]. However, it is observed from Figure $2 b$ that there are significant differences in the total impedance of samples immersed in different solutions, which suggests that after addition of different amounts of $\mathrm{NaCl}$ during $1 \mathrm{~h}$ of exposure, $\mathrm{Cl}^{-}$ions could break the passive 
film. There is a possibility that once the exposure duration is extended, the total impedance would decrease significantly. Thus, the corrosion characteristics of samples were studied over extended periods.


Figure 3. EIS plots for (a) Nyquist and (b) Bode spectra after $48 \mathrm{~h}$ of exposure. 



Figure 4. EIS plots for (a) Nyquist and (b) Bode spectra after $168 \mathrm{~h}$ of exposure.

The Bode phase angles of steel rebars after $1 \mathrm{~h}$ of immersion are depicted in Figure $2 \mathrm{~b}$. It is observed that the steel rebar immersed in SP-0 solution exhibited two times more constants: one from 2 to $0.08 \mathrm{~Hz}$ at $-80^{\circ}$ and another at lower frequencies, i.e., $0.01 \mathrm{~Hz}$ at $-56^{\circ}$, which is attributed to formation of strong passive films, i.e., Zwitterion-Fe complex. Alternatively, once $0.51 \mathrm{M} \mathrm{NaCl}$ was added in SP + 0.115M LA, i.e., SP1, the maxima shifted at a lower angle, i.e., $-70^{\circ}$ compared to SP-0. However, broadening from the middle to low studied frequencies revealed that the passive film's properties were retained. This means that $0.51 \mathrm{M} \mathrm{NaCl}$ is not enough to break the strong passive film. However, the steel rebar exposed to SP-2 solution exhibited shifting in terms of the phase angle maxima toward the middle frequency, and the asymmetric capacitive loop becomes sharp. The shifting 
of the capacitive loop at $-75^{\circ}$ on $8 \mathrm{~Hz}$ revealed that the passive film became weak. Thus, there is probability that if exposure periods increased, the passive films would start to deteriorate, i.e., the initiation of corrosion phenomena occurs. In subsequent paragraphs, we have studied the effect of $\mathrm{Cl}^{-}$ions on deterioration of passive films over extended periods of exposure.

The EIS spectra of the steel rebar immersed in different solutions after $48 \mathrm{~h}$ are shown in Figure 3. The magnitude of Nyquist plots of all samples decreased (Figure 3a) compared to $1 \mathrm{~h}$ of immersion revealing the breakdown of passive film. However, there is no significant difference in the magnitude reduction in Nyquist plots of SP-0 and SP-1, while SP-2 decreased significantly. This result suggests that SP-0 and SP-1 retained their passive properties, but SP-2 started to deteriorate. The EIS results show that passive films are initially very strong, adherent, and protective, which required $0.85 \mathrm{M} \mathrm{NaCl}$ and $48 \mathrm{~h}$ to breakdown the passive film and to initiate the corrosion phenomena at the steel rebarsolution interface. Moreover, the reduction in magnitude of Nyquist of $\mathrm{NaCl}$ added samples suggest that $\mathrm{Cl}^{-}$ions are attacking onto the passive film and weakening the passive film. Initially, $\mathrm{Cl}^{-}$ions interact with $-\mathrm{NH}_{3}{ }^{+}$(Zwitterion) in the Zwitterion-Fe complex, which resulted in the formation of weak bonds between Zwitterion and Fe $[18,27,34]$. Thus, a $\mathrm{Cl}$-(Zwitterion)-Fe complex is formed rather than a Zwitterion-(Cl)-Fe complex. In the case of high amounts of $\mathrm{NaCl}$, i.e., $\mathrm{SP}-2, \mathrm{Cl}^{-}$ions are appear in significant amounts, and they are able to form a Cl-(Zwitterion)-Fe complex, but some unreacted $\mathrm{Cl}^{-}$ions ingress towards the steel surface and initiate corrosion reactions. This observation is well-corroborated with $\mathrm{OCP}$ results where, after $48 \mathrm{~h}$ of exposure, it activated and initiated corrosion reactions.

The Bode modulus results after $48 \mathrm{~h}$ of immersion are shown in Figure $3 \mathrm{~b}$. There is no significant difference in the total impedance of steel rebars immersed in the SP-1 solution compared to $1 \mathrm{~h}$ revealing that $0.51 \mathrm{M} \mathrm{NaCl}$ is not able to break the passive film immersed in the SP + 0.115 M LA solution. However, in the case of SP-2, the total impedance was reduced by three times than $1 \mathrm{~h}$, which suggests that corrosion initiation started to occur after $48 \mathrm{~h}$ of immersion. This finding reveals that the passive film formed in SP $+0.115 \mathrm{M}$ $\mathrm{NaCl}$ solution required $0.85 \mathrm{M} \mathrm{NaCl}$ and $48 \mathrm{~h}$ to breakdown the passive film and to initiate corrosion. Meanwhile, $\mathrm{Cl}^{-}$ions in this solution also formed a Cl-(Zwitterion)-Fe complex, but some unreacted $\mathrm{Cl}^{-}$ions during complex formation locally attacked the steel rebar and initiated corrosion reactions.

The steel rebar immersed in different solutions up to $48 \mathrm{~h}$ and the phase Bode plots results are shown in Figure $3 \mathrm{~b}$. The steel rebar immersed in SP-0 solution has maintained its phase maxima from 5 to $0.10 \mathrm{~Hz}$ at $-80^{\circ}$, revealing the protective properties of the film. Broadening in the phase angle maxima of steel rebar immersed in SP-1 solution is observed from 31 to $0.5 \mathrm{~Hz}$ at $-70^{\circ}$. This result suggests that steel rebar immersed in SP-1 solution retained its protective properties even after $48 \mathrm{~h}$ owing to the formation of $\mathrm{Cl}$-(Zwitterion)-Fe complex. Alternatively, there is sharp asymmetric capacitive loop observed in the SP-2 solution exposed sample at $-75^{\circ}$ on $6 \mathrm{~Hz}$. There is an interesting observation found for the rebar immersed in SP-2 solution at $0.01 \mathrm{~Hz}$ where phase maxima are found to be $-12^{\circ}$, while it is $-26^{\circ}$ after $1 \mathrm{~h}$ of exposure. The shifting in maxima towards a lower angle at $0.01 \mathrm{~Hz}$ revealed the initiation of corrosion. Thus, significant reduction in total impedance was observed after $48 \mathrm{~h}$ of exposure.

The EIS plots after $168 \mathrm{~h}$ of immersion are illustrated in Figure 4 . The Nyquist plots of samples are shown in Figure 4a. The steel rebar exposed to SP-0 solution retained its properties as observed after $48 \mathrm{~h}$ of exposure, which suggests that passive films strengthen with exposure periods in SP + 0.115 M LA solution owing to the formation of a ZwitterionFe complex. However, the $\mathrm{NaCl}$ added sample, i.e., SP-1, exhibited reductions in magnitude of Nyquist plots than earlier periods of exposure owing to the interaction of $\mathrm{Cl}^{-}$ions with Zwitterion. In this case, electrostatic interactions between Zwitterion and Fe decreased, resulting in weakening of passive films. Alternatively, the steel rebar exposed to the SP-2 solution shows identical magnitudes in Nyquist plots as observed after $48 \mathrm{~h}$ of immersion. 
This result reveals that once the corrosion reaction started after $48 \mathrm{~h}$ of exposure, it did not significantly enhance or increase corrosion; rather it maintained the properties of the film.

The total impedances of the samples after $168 \mathrm{~h}$ of immersion are shown in Figure $4 \mathrm{~b}$. The steel rebars exposed to SP-0 and SP-2 solutions maintained their total impedance obtained after $48 \mathrm{~h}$ of exposure, but SP-1 was observed to be slightly decreased. In the case of SP-0, the passive films are strengthened and stabilized due to the surface coverage of the passive film. However, in the case of SP-2, it was found that once the corrosion has started after $48 \mathrm{~h}$ of immersion in the presence of high amount of $\mathrm{Cl}^{-}$ions, the Cl(Zwitterion)-Fe complex stabilized and controlled further corrosion reaction. Therefore, this demonstrated identical impedance by the formation of complexes as observed in earlier exposure periods. However, the steel rebar exposed to SP-1 solution exhibited reduction in total impedance compared to earlier exposure periods, but it is higher than $\mathrm{SP}-2$ owing to weakened Fe-(Zwitterion)-Cl/Cl-(Zwitterion)-Fe complex. The electrostatic interaction between Fe-Zwitterion is weak compared to the Zwitterion-Cl complex because the $-\mathrm{COO}^{-}$group of Zwitterion has lower affinity with Fe compared to the Zwitterion-Cl complex [27,38-40].

The results of phase angle Bode plots after $168 \mathrm{~h}$ of exposure are shown in Figure $4 \mathrm{~b}$. The steel rebar immersed in SP-0 solution maintained its phase angle maxima even after $168 \mathrm{~h}$ of exposure around $-80^{\circ}$ from 2 to $0.08 \mathrm{~Hz}$. This result suggests that steel rebar surface is protected by the adsorbed Zwitterion that formed a protective film, i.e., the passive film strengthened its resistive properties by forming a uniform and homogeneous layer of Zwitterion-Fe complex within the exposure period. Furthermore, the steel rebar immersed in SP-1 solution exhibited phase maxima at $-75^{\circ}$ on $0.96 \mathrm{~Hz}$, but this asymmetric capacitive loop is sharp; on the other hand, there was broadening in peak from middle to low frequencies after $48 \mathrm{~h}$ of exposure. There is an interesting observation where the maxima are found at $-24^{\circ}$ on $0.01 \mathrm{~Hz}$, and it is much lower than earlier immersion periods. The lowering in maxima and sharpness in the asymmetric capacitive loop indicates that this sample started to reduce the properties of passive film at longer duration of exposure. Since the steel rebar kept in SP-2 solution exhibited phase angle maxima at $-76^{\circ}$ on $11 \mathrm{~Hz}$, the shifting of maxima in middle frequencies and sharpness in asymmetric capacitive loops indicates the initiation of corrosion reactions. Moreover, the shifting of maxima towards $0.01 \mathrm{~Hz}$ at $-11^{\circ}$ revealed the initiation of corrosion at steel rebar-solution interface. The unreacted $\mathrm{Cl}^{-}$ions with Zwitterion in the solution ingress through the Zwitterion-Fe layer and initiated the corrosion reaction. Thus, the lowest total impedance is found. There is no difference in phase angle maxima of steel rebar immersed in SP-2 solution at $0.01 \mathrm{~Hz}$ between $48 \mathrm{~h}$ and $168 \mathrm{~h}$, revealing the stabilization of corrosion reaction owing to the formation of a Fe-(Zwitterion)-Cl complex. This result is well corroborated with OCP plots where the OCP of this sample stabilized after $72 \mathrm{~h}$ of exposure. There is the possibility that film thickness is high, which stifled the ingress of $\mathrm{NaCl}$ towards steel rebar surface. Thus, stabilized impedance is observed after $168 \mathrm{~h}$ of exposure.

The electrical equivalent circuit (EEC) has been used to fit EIS data and to extract electrochemical parameters. Figure 5a was used to fit EIS data of the steel rebar exposed to SP-0 solution with different exposure periods where a single circuit is fitted with one time constant and Warburg impedance [41,42]. In this EEC, $R_{s}, C P E$, and $R_{p}$ are the solution resistance, constant phase element, and polarization resistance, respectively. The presence of CPE is due to the heterogeneity of the surface. Alternatively, EIS plots of steel rebar immersed in SP-1 and SP-2 solutions are fitted with one EEC containing two times constant, as shown in Figure $5 b$ [43-46]. In this EEC, $R_{c t}$ and $C P E_{c t}$ are the charge transfer resistance and constant phase element for charge transfer, respectively. 


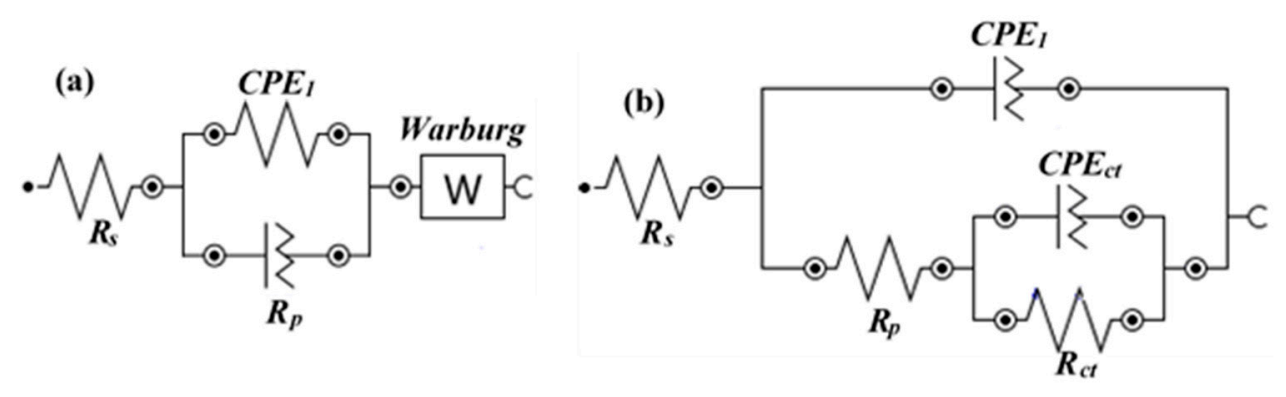

Figure 5. EEC of (a) SP-0 and (b) SP-1 to SP-2 samples from 1-168 h of exposure.

The CPE coefficient $\left(Q_{\text {eff }}\right)$ can be calculated by Equation (1) with the CPE exponent $(n) \neq 1[47]$

$$
Q_{e f f}=\sin \left(\frac{n \pi}{2}\right) \frac{-1}{Z_{j}(f)(2 \pi f)^{n}}
$$

In Equation (1), $f$ is frequency. However, $Q_{\text {eff }}$ becomes capacitance $\left(C_{e f f}\right)$ if $n$ is 1 . Therefore, Equation (1) can be rewritten as follows.

$$
Q_{e f f}=C_{e f f}=\frac{-1}{Z_{j}(f)(2 \pi f)}
$$

Due to exposure of rebars in solution, surface heterogeneity is found. Thus, $C_{\text {eff }}$ can be determined by the CPE coefficient $(Q)$ [48-50].

$$
C_{e f f}=Q^{1 / n} R_{S}^{(1-n) / n}
$$

The thickness of the passive film $\left(t_{f}\right)$ is calculated on the basis of obtained $C_{\text {eff }}$ as follows [51]:

$$
t_{f}=\frac{A \cdot \varepsilon \varepsilon_{0}}{C e f f}
$$

where $A$ is the surface exposed area of steel rebar, and $\varepsilon$ and $\varepsilon_{0}$ are permittivity of steel and permittivity of vacuum, respectively.

The electrochemical parameters are calculated by fitting EIS plots in suitable EEC, and the results are shown in Table 3 and Figure 6. The $R_{s}$ value of steel rebar exposed to SP-0 solution is higher and found to be $22-28 \Omega \cdot \mathrm{cm}^{2}$ compared to $\mathrm{NaCl}$ added solutions, as shown in Table 3. Initially L-arginine dissolved in the solution, but once it was exposed to steel rebar, it formed a Zwitterion-Fe complex at the steel rebar-solution interface where all L-arginine might be consumed during the formation of this complex. The solubility of this complex might be significantly lower; thus, the ion concentrations in this solution also becomes lower. Therefore, it shows the highest $R_{S}$ values compared to the others. Alternatively, once $\mathrm{NaCl}$ was added in the solution, the ions' mobility and concentration increased; thus, lower $R_{S}$ values were observed. It can be observed from Table 3 that the steel rebar immersed in SP-2 solution exhibits the lowest $R_{S}$ values compared to the others owing to the highest amount of $\mathrm{NaCl}$ in solution. The $R_{p}$ value of the samples gradually decreased as immersion time increased (Figure 6), and this is attributed to the diffusion of Zwitterion-Fe complex by coordinating with oxygen, which results in Warburg impedance (W) in the SP-0 solution while this is not observed in SP-1 and SP-2 owing to the interaction of $\mathrm{Cl}^{-}$ions with Zwitterion-Fe. This causes the ingress of $\mathrm{Cl}^{-}$ions in SP-1 and SP-2 solutions, which weakens the Zwitterion-Fe complex. In the case of $\mathrm{SP}-2, \mathrm{Cl}^{-}$ions appear in significant amounts, which perturb the passive film and initiated corrosion reaction after $48 \mathrm{~h}$ of exposure. This result well correlates with the OCP plots (Figure 1). Once the $R_{p}$ values decreased, $C_{\text {eff }}$ increased with exposure periods. The reduction in $R_{p}$ values in SP-2 solution is significant up to $48 \mathrm{~h}$, but it is stabilized after $168 \mathrm{~h}$ of exposure. Initially, W is lower in SP-0, but it is increased around two times as immersion time increased up to $48 \mathrm{~h}$ (Table 3), which suggests that oxygen (from Zwitterion) diffused towards the surface of 
the steel rebar but decreased after $168 \mathrm{~h}$ again (Table 3). It can be observed from Table 3 that $n_{1}$ values of all samples after $1 \mathrm{~h}$ of exposure is found to be $\geq 0.8$, revealing that the surface becomes homogeneous $[45,52]$. However, as the exposure periods are extended, the steel rebar exposed to SP-0 and SP- 1 solutions attain its values $\geq 0.8$, which suggests that passive films are protective and cannot be affected by aggressive ions in the solution, while it decreased for SP-2. This result suggests that an amount more than $0.51 \mathrm{M} \mathrm{NaCl}$ results the passive film breaking and the surface becomes heterogeneous; thus, pitting corrosion can be observed. The $R_{c t}$ values of steel rebar exposed to SP- 1 and SP-2 solutions increased with exposure periods (Table 3). Moreover, SP-1 exhibiting greater $R_{c t}$ values than SP-2. This is attributed to the formation of protective $\mathrm{Cl}$-(Zwitterion)-Fe complex as passive films, but $\mathrm{Cl}^{-}$ions in SP-2 solution are significant, which perturbs the passive film. The $n_{c t}$ values of steel rebar exposed to SP-1 and SP-2 solutions increased as immersion periods increased (Table 3). However, in the case of SP- $1, n_{c t}$ values are close to 0.8 , suggesting the formation of homogenous passive film, while SP-2 is found to be at the maximum of 0.65 after $168 \mathrm{~h}$ of exposure, revealing its defective and heterogeneous properties. $Q_{c t}$ values of steel rebar exposed to SP-2 solution are higher than SP-1, revealing the capacitive properties of the film. The thickness of the film with exposure periods increased in $\mathrm{NaCl}$ containing samples, and this is attributed to the formation of the Cl-(Zwitterion)-Fe complex, while SP-0 exhibited lower values and stabilized at $35-38 \mathrm{~nm}$ (Table 3). There is no $\mathrm{NaCl}$; thus, SP-0 cannot form the above complex. Thus, it reflects lower values.

Table 3. Electrochemical parameters of steel rebar immersed in different solutions.

\begin{tabular}{|c|c|c|c|c|c|c|c|c|c|}
\hline \multirow[b]{3}{*}{ Time (h) } & \multirow[b]{3}{*}{ Sample ID } & \multicolumn{8}{|c|}{ Electrochemical Parameters } \\
\hline & & \multirow[b]{2}{*}{$R_{s}\left(\Omega \cdot \mathrm{cm}^{2}\right)$} & \multicolumn{2}{|c|}{$C P E_{1}$} & \multirow[b]{2}{*}{$R_{c t}\left(\mathrm{k} \Omega \cdot \mathrm{cm}^{2}\right)$} & \multicolumn{2}{|c|}{$C P E_{c t}$} & \multirow{2}{*}{$\begin{array}{c}\text { Warburg } \\
\left(1 \times 10^{-3}\right) \\
\left(\Omega \cdot \mathrm{cm}^{2} \cdot \mathrm{s}^{0.5}\right)\end{array}$} & \multirow[b]{2}{*}{$t_{f}(\mathrm{~nm})$} \\
\hline & & & $\begin{array}{c}Q_{1}\left(1 \times 10^{-5}\right) \\
\left(\Omega^{-1} \cdot \mathrm{cm}^{-2} \cdot \mathrm{s}^{n}\right)\end{array}$ & $n_{1}$ & & $\begin{array}{c}Q_{c t} \\
\left(1 \times 10^{-5}\right) \\
\left(\Omega^{-1} \cdot \mathrm{cm}^{-2} \cdot \mathbf{s}^{n}\right)\end{array}$ & $n_{c t}$ & & \\
\hline \multirow{4}{*}{1} & SP-0 & $28( \pm 0.13)$ & $10.3( \pm 0.06)$ & $0.90( \pm 0.02)$ & & & & \multirow[t]{3}{*}{$4.66( \pm 0.27)$} & $38.35( \pm 2.72)$ \\
\hline & SP-1 & $14( \pm 0.08)$ & $14.2( \pm 0.13)$ & $0.81( \pm 0.02)$ & $4.10( \pm 0.11)$ & $12.5( \pm 1.25)$ & $0.72( \pm 0.02)$ & & $45.02( \pm 2.97)$ \\
\hline & SP-2 & $10( \pm 0.18)$ & $17.2( \pm 0.76)$ & $0.80( \pm 0.01)$ & $1.20( \pm 0.04)$ & $19.4( \pm 0.99)$ & $0.62( \pm 0.01)$ & & $62.75( \pm 4.08)$ \\
\hline & SP-0 & $22( \pm 0.27)$ & $13.0( \pm 0.15)$ & $0.88( \pm 0.01)$ & & & & \multirow{3}{*}{$7.13( \pm 0.63)$} & $35.10( \pm 2.07)$ \\
\hline \multirow[t]{3}{*}{48} & SP-1 & $12( \pm 0.10)$ & $14.6( \pm 0.10)$ & $0.81( \pm 0.01)$ & $4.81( \pm 0.08)$ & $11.1( \pm 0.08)$ & $0.76( \pm 0.04)$ & & $60.90( \pm 3.84)$ \\
\hline & SP-2 & $7( \pm 0.04)$ & $19.8( \pm 1.56)$ & $0.76( \pm 0.05)$ & $1.24( \pm 0.11)$ & $18.8( \pm 1.50)$ & $0.63( \pm 0.04)$ & & $62.75( \pm 4.20)$ \\
\hline & SP-0 & $22( \pm 0.30)$ & $11.9( \pm 0.78)$ & $0.89( \pm 0.01)$ & & & & \multirow[t]{3}{*}{$3.79( \pm 0.45)$} & $36.33( \pm 2.62)$ \\
\hline \multirow[t]{2}{*}{168} & SP-1 & $13( \pm 0.01)$ & $15.4( \pm 0.02)$ & $0.80( \pm 0.05)$ & $5.10( \pm 0.41)$ & $10.6( \pm 0.02)$ & $0.76( \pm 0.06)$ & & $64.71( \pm 3.56)$ \\
\hline & SP-2 & $7( \pm 0.05)$ & $20.2( \pm 0.03)$ & $0.74( \pm 0.02)$ & $2.07( \pm 0.01)$ & $17.5( \pm 0.12)$ & $0.65( \pm 0.01)$ & & $62.75( \pm 4.20)$ \\
\hline
\end{tabular}

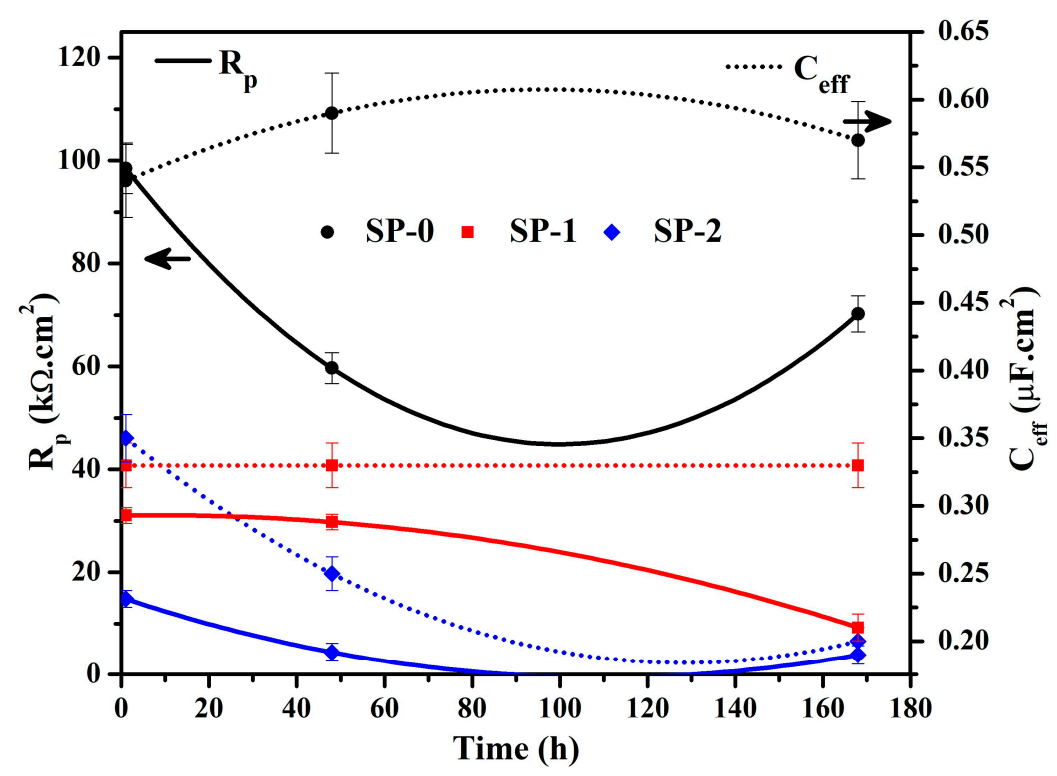

Figure 6. $R_{p}$ and $C_{e f f}$ in different solutions with time. 


\subsubsection{Potentiodynamic Polarization Studies after $168 \mathrm{~h}$ of Exposure in Different Solutions}

The potentiodynamic polarization results of steel rebar after $168 \mathrm{~h}$ of immersion are shown in Figure 7. The cathodic curve results indicate oxygen reduction reactions. During cathodic scanning, the Zwitterion-Fe complex reduced, resulting in increased cathodic current density. The steel rebar immersed in SP-2 solution exhibits the highest cathodic current due to the development of a defective passive layer by $\mathrm{Cl}^{-}$ions, which weakens the $\mathrm{Cl}$-(Zwitterion)-Fe complex. Alternatively, during anodic scanning, the current density of SP-0 sample was found to be lowest followed by SP-1 and SP-2. The anodic currents of steel rebar exposed to SP-1 and SP-2 solutions are higher than SP-0 due to the presence of $\mathrm{Cl}^{-}$ions, which destabilized the Zwitterion-Fe complex and enhanced corrosion reactions. The steel rebar immersed in SP-2 solution exhibited pit formation during anodic scanning at $60 \mathrm{mV}\left(E_{\text {pit }}\right)$ on $0.97 \mathrm{~mA}\left(i_{\text {pit }}\right)$. This result suggests that excess $\mathrm{Cl}^{-}$ions broke the passive film, i.e., Zwitterion-Fe complex, and reached the steel rebar surface. The steel rebar immersed in SP-0 solution showed breakdown potential during anodic scanning, revealing the formation of metastable passive film.

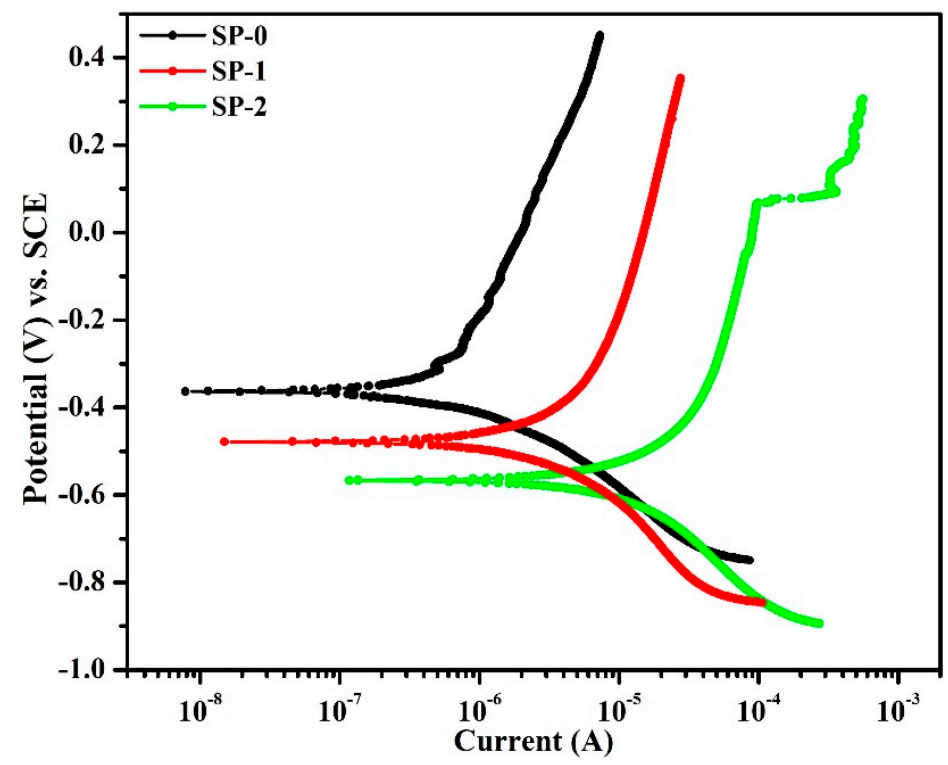

Figure 7. Potentiodynamic polarization after $168 \mathrm{~h}$ immersion in different solutions.

Electrochemical parameters were extracted after the fitting of potentiodynamic polarization curves in Tafel slopes, and the results are illustrated in Table 4. This table shows that the corrosion potential $\left(E_{\text {corr }}\right)$ of the samples shifted towards the active direction once $\mathrm{NaCl}$ is added in solution. The $E_{\text {corr }}$ values of steel rebars immersed in SP-0, SP-1. and SP-2 solutions were found to be $-363,-478$, and $-566 \mathrm{mV}$ vs. SCE, respectively. This result suggests that the steel rebar immersed in SP-2 solution shows the corrosion of steel rebar $[16,20,35-37]$. The corrosion current densities $\left(i_{\text {corr }}\right)$ of steel rebar immersed in SP-0, SP-1, and SP-2 solutions are found to be $0.10,0.45$, and $1.96 \mu \mathrm{A} \cdot \mathrm{cm}^{-2}$, respectively. Liu et al. [19] have suggested that if the $i_{\text {corr }}$ values are $<0.1 \mu \mathrm{A} \cdot \mathrm{cm}^{-2}$, then it is considered to be at passive levels and it is considered to be at low corrosion levels from $0.1 \mu \mathrm{A} \cdot \mathrm{cm}^{-2}$ to $<0.5 \mu \mathrm{A} \cdot \mathrm{cm}^{-2}$. However, once the $i_{\text {corr }}$ value is within 0.5 to $<1 \mu \mathrm{A} \cdot \mathrm{cm}^{-2}$, then it is considered as severe corrosion. From the present studies, it can be concluded that the passive layer actually deteriorated with exposure to $\mathrm{NaCl}$ for $\mathrm{SP}-1$, but it remains a stable layering in contrast to SP- 2 where $\mathrm{Cl}^{-}$ions ooze onto the passive film with time; therefore, the steel rebars immersed in SP-0, SP-1, and SP-2 solutions are observed to be at passive, low, and severe corrosion levels, respectively. Moreover, this finding revealed that $0.115 \mathrm{M}$ LA containing steel rebar forms a passive film that can sustain up to $0.51 \mathrm{M} \mathrm{NaCl}$ during the breakdown of the passive film, but severe corrosion can occur once $\mathrm{NaCl}$ is increased up to $0.85 \mathrm{M}$ at longer durations. 
Table 4. Electrochemical parameters of steel rebar.

\begin{tabular}{ccccc}
\hline \multirow{2}{*}{ Sample ID } & \multicolumn{4}{c}{ Electrochemical Parameters } \\
\cline { 2 - 5 } & $\begin{array}{c}\boldsymbol{E}_{\text {corr }}(\mathbf{m V}) \mathbf{v s .} \\
\mathbf{S C E}\end{array}$ & $\boldsymbol{i}_{\text {corr }}\left(\boldsymbol{\mu \mathbf { A } \cdot \mathbf { c m } ^ { - 2 } )}\right.$ & $\begin{array}{c}\text { Corrosion Level } \\
{[19]}\end{array}$ & $\begin{array}{c}\boldsymbol{C} \cdot \boldsymbol{R} . \\
\left(\boldsymbol{\mu m} \cdot \mathbf{y e a r}^{-\mathbf{1}}\right)\end{array}$ \\
\hline SP-0 & $-363( \pm 1.25)$ & $0.10( \pm 0.008)$ & $\begin{array}{c}\text { Passive } \\
\text { condition }\end{array}$ & $1.16( \pm 0.009)$ \\
SP-1 & $-478( \pm 1.89)$ & $0.45( \pm 0.05)$ & Low & $5.23( \pm 0.52)$ \\
SP-2 & $-566( \pm 1.83)$ & $1.96( \pm 0.15)$ & Severe & $22.77( \pm 1.59)$ \\
\hline
\end{tabular}

The corrosion rate (C.R.) of the samples immersed in different solutions is calculated by $i_{\text {corr }}$ values using the following equation [53], and the results are shown in Table 4:

$$
\text { Corrosionrate }\left(\mu \mathrm{m} \cdot \mathrm{year}^{-1}\right)=\frac{3.27 \times i_{\text {corr }} \times E . W}{d}
$$

where $i_{\text {corr }}$ is the corrosion current density calculated by dividing the total exposed surface area of the steel rebar from the corrosion current; E.W. is the equivalent weight $\left(\mathrm{g} \cdot \mathrm{mol}^{-1}\right)$; and $d$ is the density $\left(\mathrm{g} \cdot \mathrm{cm}^{-3}\right)$ of the Fe. The corrosion rates of steel rebar immersed in SP-0, SP-1, and SP-2 solution are found to be 1.16, 5.23, and $22.77 \mu \mathrm{m} \cdot$ year $^{-1}$. The steel rebar immersed in SP-1 and SP-2 solutions exhibited almost 4.5 and 20 times higher corrosion rate compared to $\mathrm{SP}-0$, respectively.

\subsection{Characterization}

Surface Morphology of Passive Film by SEM

The SEM images of passive films formed onto the steel rebar surface after $168 \mathrm{~h}$ of immersion in different solutions are shown in Figure 8. Figure 8a shows that the steel rebar immersed in SP-0 solution exhibited agglomeration in the passive film. Initially L-arginine (LA) was dissolved in the SP solution, but it started to react and form small Zwitterion-Fe complex once the steel rebar is immersed. As the exposure periods increased, most of the LA interacted with Fe and formed many Zwitterion-Fe complex clusters and adsorbed onto the steel rebar. Moreover, once $0.51 \mathrm{M} \mathrm{NaCl}$ was added in the SP + 0.115 M LA solution, i.e., SP-1, interaction between $\mathrm{Cl}^{-}$ions with each Zwitterion-Fe complex was observed, resulting in the formation of the $\mathrm{Cl}$-(Zwitterion)-Fe complex. Thus, the thickness of the passive film is greater than SP-0 (Table 3). This complex is adsorbed onto the rebar (Figure $8 \mathbf{b}$ ). However, due to the smaller size of $\mathrm{Cl}^{-}$ions remaining in the solution compared to the intermolecular pores of the adsorbed layer that permit slow propagation, the result is the initiation of corrosion, which is observed in Figure 7. Once the $\mathrm{Cl}^{-}$ions interacted with the Zwitterion-Fe complex, the particles size of the cluster decreased and was regularly adsorbed; thus, dense morphology was observed (Figure 8b). Moreover, as $\mathrm{NaCl}$ increased up to $0.85 \mathrm{M}$ in SP $+0.115 \mathrm{M} \mathrm{LA}$, i.e., SP-2, and was exposed up to $168 \mathrm{~h}$, the excess amount of $\mathrm{Cl}^{-}$ions penetrated through the $\mathrm{Cl}$-(Zwitterion)-Fe complex and initiated corrosion reactions; thus, pitting is observed in SEM (Figure 8c), and this result is well correlated with potentiodynamic polarization (Figure 7). As the $\mathrm{NaCl}$ amount increased, the particle size of the complex was reduced; thus, irregularity and vacancy between two particles are observed in Figure 8c.

EDS analyses of the passive film are shown in Table 5. The amount of $\mathrm{Na}$ and $\mathrm{Cl}$ increased once the $\mathrm{NaCl}$ amount increased in the solution. The $\mathrm{Cl}$ is found to be highest in the SP-2 solution, which revealed that $\mathrm{Cl}^{-}$ions deposited onto the passive film resulted in highest corrosion rates. The results of $\mathrm{Na}, \mathrm{K}$, and $\mathrm{Ca}$ were a consequence of the composition of the pore solution where $\mathrm{NaOH}, \mathrm{KOH}$, and $\mathrm{CaO}$ were added. $\mathrm{Ca}$ was found in greater amounts compared to $\mathrm{Na}$, and $\mathrm{K}$ is attributed to less dissolution of $\mathrm{CaO}$ and atmospheric carbonation. The presence of around $17-22 \% \mathrm{O}$ revealed the formation of the passive film through the adsorption of LA molecules. The presence of around $1.5-2 \% \mathrm{~N}$ in all samples revealed that passive films contain LA, which formed a Zwitterion-Fe complex. 

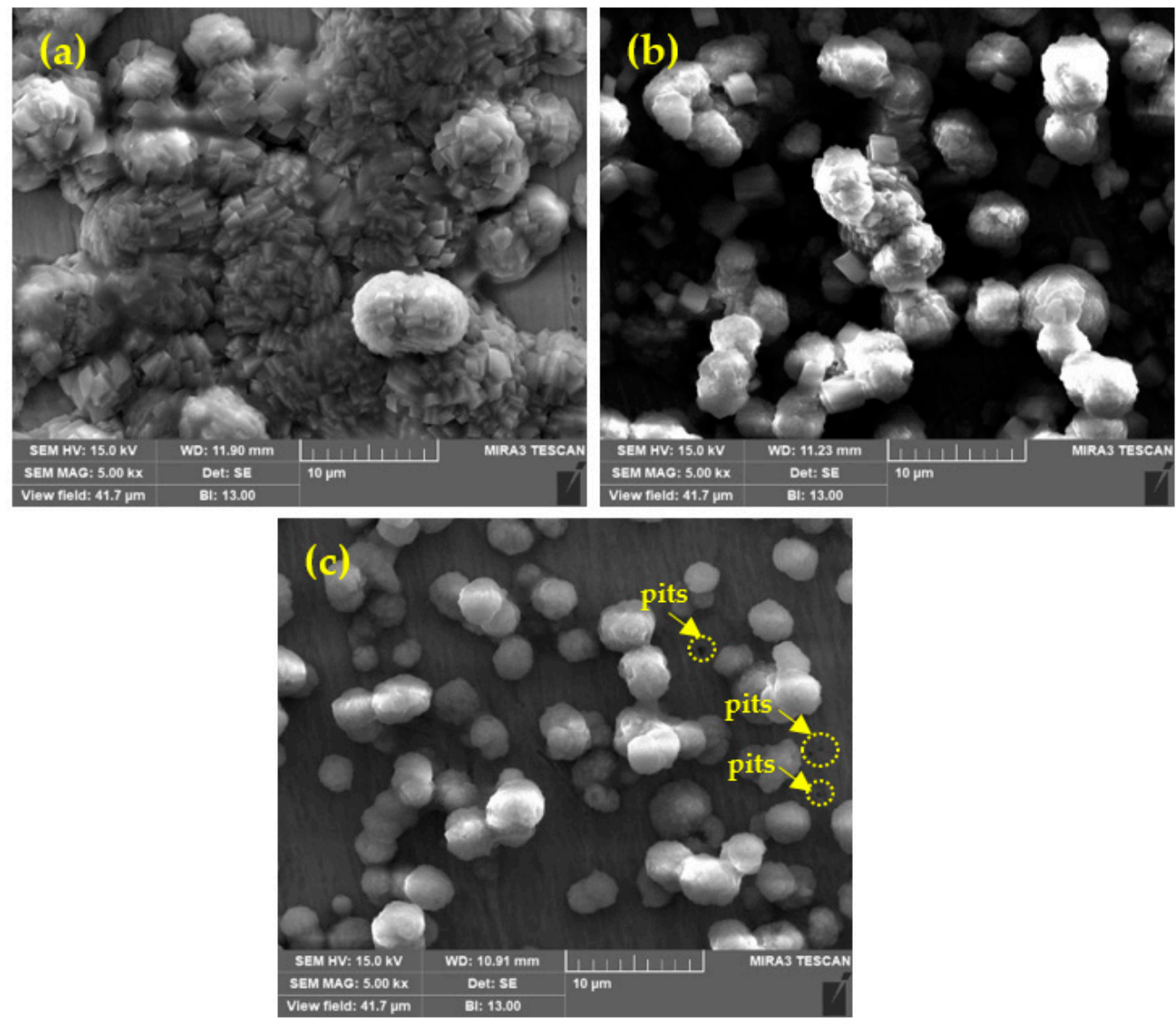

Figure 8. SEM after $168 \mathrm{~h}$ of immersion in (a) SP-0, (b) SP-1, and (c) SP-2 solutions.

Table 5. EDS analysis of passive film.

\begin{tabular}{ccccccccc}
\hline \multirow{2}{*}{ Sample ID } & \multicolumn{7}{c}{ Elements (Wt.\%) } \\
\cline { 2 - 9 } & $\mathbf{O}$ & $\mathbf{N a}$ & $\mathbf{C l}$ & $\mathbf{K}$ & $\mathbf{C a}$ & $\mathbf{N}$ & $\mathbf{C}$ & $\mathbf{F e}$ \\
\hline SP-0 & $21.87( \pm 3.82)$ & $2.12( \pm 0.26)$ & - & $0.42( \pm 0.12)$ & $18.28( \pm 1.38)$ & $2.04( \pm 0.22)$ & $11.19( \pm 1.31)$ & Balance \\
SP-1 & $19.12( \pm 2.33)$ & $3.64( \pm 0.28)$ & $2.59( \pm 0.34)$ & $0.56( \pm 0.07)$ & $17.39( \pm 1.36)$ & $1.94( \pm 0.19)$ & $11.15( \pm 1.29)$ & Balance \\
SP-2 & $17.36( \pm 2.26)$ & $3.71( \pm 0.35)$ & $4.04( \pm 0.46)$ & $0.32( \pm 0.09)$ & $14.64( \pm 1.88)$ & $1.57( \pm 0.22)$ & $11.49( \pm 0.80)$ & Balance \\
\hline
\end{tabular}

\subsection{Plausible Mechanism for Initiation of the Corrosion Reaction}

L-arginine (LA) is an amino acid that forms Zwitterion, i.e., protonated amino acid [27]. Amino acid can be used as inhibitor, and it is most effective when added with electronegative elements, i.e., halide ions [34]. A Zwitterion-Cl complex would form once the $\mathrm{Cl}^{-}$ions are present in the solution. In LA containing SP solutions, the negative end of Zwitterion reacts with positively charged Fe metal and forms a Zwitterion-Fe complex, as shown in Figure 9a, up to $144 \mathrm{~h}$ of immersion. At higher immersion periods, the passive film, i.e., Zwitterion-Fe complex, strengthened the properties; thus, the highest impedance is observed. However, once $0.51 \mathrm{M} \mathrm{NaCl}$ was added into the solution, i.e., SP-1, the $\mathrm{Cl}^{-}$ ions tried to ingress through the passive film, but the positive end of Zwitterion interacted and formed Zwitterion-Cl complexes, as shown in step 1 of Figure 9b, which are adsorbed onto the steel surface (step 2 of Figure $9 \mathrm{~b}$ ) rather than being subject to corrosion. In this case, the $\mathrm{Cl}^{-}$ions were limited and interacted with Zwitterion ions and formed Fe-(Zwitterion)-Cl/Cl-(Zwitterion)-Fe complexes; thus, protection is observed. Moreover, $\mathrm{Cl}^{-}$ions observed in lesser amounts in SP-1 solution entered through the adsorbed Fe(Zwitterion)-Cl complex, but once the amount of $\mathrm{NaCl}$ increased up to $0.85 \mathrm{M}$, i.e., SP-2, some amount of $\mathrm{Cl}^{-}$ions interacted with Zwitterion and formed Zwitterion-Cl complexes. However, the excess amount of $\mathrm{Cl}^{-}$ions penetrated through the adsorbed film and reached 
the steel rebar surface, which resulted in the initiation of corrosion reaction, as shown in Figure 9c. From this finding, it can be inferred that $0.115 \mathrm{M}$ LA can sustain up to $0.51 \mathrm{M}$ $\mathrm{NaCl}$. The chloride threshold of LA in the present study is $0.51 \mathrm{M} \mathrm{NaCl}$, which can protect steel rebars up to $168 \mathrm{~h}$ of exposure.


Figure 9. Schematic of (a) SP-0 for formation of Zwitterion-Fe complex as passive film, (b) interaction of $\mathrm{Cl}^{-}$ions with passive film in SP-1, and (c) SP-2 solutions onto the steel rebar surface.

\section{Conclusions}

L-arginine is an eco-friendly corrosion inhibitor, which is adsorbed onto rebar surfaces and mitigates corrosion. In this study, a fixed amount $0.115 \mathrm{M}$ LA has been used in an SP solution (SP-0) to initiate the growth of a passive film for $144 \mathrm{~h}$. LA has been adsorbed onto the rebar by forming a Zwitterion-Fe complex. Once the proper passive film has been formed after $144 \mathrm{~h}$, different amounts of $\mathrm{NaCl}$, i.e., $0.51 \mathrm{M}$ (SP-1) and $0.85 \mathrm{M} \mathrm{NaCl}$ (SP-2), are added in order to study the effect of $\mathrm{Cl}^{-}$ions during the breakdown of the passive film and during the initiation of corrosion reactions. It can be observed from the present study that the steel rebar immersed in SP-0 solution exhibited the highest $R_{p}$ due to the formation of a protective passive film than compared to $\mathrm{NaCl}$ added to solutions with immersion periods. Once $\mathrm{NaCl}$ has been added in the solution, $\mathrm{Cl}^{-}$ions initially interacted with the Zwitterion-Fe complex and formed a Cl-(Zwitterion)-Fe/Fe-(Zwitterion)-Cl complex, which protected the steel rebar; thus, the $R_{c t}$ value of steel rebar immersed in SP-1 and SP-2 solutions increased with exposure periods. However, the steel rebar immersed in SP-1 solution exhibited the highest $R_{c t}$ values compared to SP-2, and this is attributed to the formation of the $\mathrm{Cl}$-(Zwitterion)-Fe complex as a protective passive film. Alternatively, SP-2 has the highest amount of $\mathrm{NaCl}$ where some amount of $\mathrm{NaCl}$ reacts with $\mathrm{Z}$ witterion-Fe and formed a Cl-(Zwitterion)-Fe complex, but the excess amount of $\mathrm{NaCl}$ entered through the adsorbed layer/passive films and initiated corrosion reactions. However, the initiation of corrosion reaction requires some time in the SP- 2 solution; thus, after $48 \mathrm{~h}$ of exposure, the OCP value shifted towards the active direction and the impedance values decreased 
dramatically. The potentiodynamic polarization results reveal severe corrosion as well as pits formation in SP-2 solution, while SP-0 exhibited immune/passive conditions and SP-1 shows low levels of corrosion after $168 \mathrm{~h}$ of $\mathrm{NaCl}$ addition. The chloride threshold of LA in the present study was found to be $0.51 \mathrm{M} \mathrm{NaCl}$, which can protect steel rebars up to $168 \mathrm{~h}$ of exposure. The morphology of passive films by SEM reveals the formation of agglomerated and dense complex passive films in the SP-0 solution, while SP-2 shows pits and irregular morphology.

Author Contributions: Data curation, J.K.S. and S.M.; formal analysis, J.K.S. and S.M.; funding acquisition, H.-S.L. and H.-M.Y.; investigation, J.K.S. and S.M.; methodology, J.K.S. and S.M.; supervision, H.-S.L. and H.-M.Y.; writing—original draft, J.K.S., S.M., H.-S.L. and H.-M.Y.; writing-review and editing, J.K.S., S.M., H.-S.L. and H.-M.Y. All authors have read and agreed to the published version of the manuscript.

Funding: This research received no external funding.

Institutional Review Board Statement: Not applicable.

Informed Consent Statement: Not applicable.

Data Availability Statement: The raw/processed data required to reproduce these findings cannot be shared at this time as the data also forms part of an ongoing study.

Acknowledgments: This work was supported by basic science research program through the National Research Foundation (NRF) of Korea funded by the Ministry of Science, ICT, and Future Planning (No. 2015R1A5A1037548).

Conflicts of Interest: All authors declare that there are no conflict of interest.

\section{References}

1. Penttala, V. Causes and mechanisms of deterioration in reinforced concrete. In Failure, Distress and Repair of Concrete Structures; Elsevier: Amsterdam, The Netherlands, 2009; pp. 3-31.

2. Poursaee, A. Corrosion of steel in concrete structures. In Corrosion of Steel in Concrete Structures; Elsevier: Amsterdam, The Netherlands, 2016; pp. 19-33.

3. Garcés, P.; Saura, P.; Méndez, A.; Zornoza, E.; Andrade, C. Effect of nitrite in corrosion of reinforcing steel in neutral and acid solutions simulating the electrolytic environments of micropores of concrete in the propagation period. Corros. Sci. 2008, 50, 498-509. [CrossRef]

4. Alonso, C.; Andrade, C.; Castellote, M.; Castro, P. Chloride threshold values to depassivate reinforcing bars embedded in a standardized OPC mortar. Cem. Concr. Res. 2000, 30, 1047-1055. [CrossRef]

5. Hausmann, D. Steel corrosion in concrete-How does it occur? Mat. Prot. 1967, 11, 19-23.

6. Gouda, V. Corrosion and corrosion inhibition of reinforcing steel: I. Immersed in alkaline solutions. Br. Corros. J. 1970, 5, 198-203. [CrossRef]

7. Vassie, P.; TRRL. Reinforcement corrosion and the durability of concrete bridges. Proc. Inst. Civ. Eng. 1984, 76, 713-723. [CrossRef]

8. Standard, B. 8110: Part 1, Structural use of concrete-Code of practice for design and construction. Br. Stand. Inst. Lond. UK 1985, 3-8.

9. Hooton, R.D.; Geiker, M.R.; Bentz, E.C. Effects of curing on chloride ingress and implications on service life. Mater. J. 2002, 99, 201-206.

10. Youping, L.; Weyers Richard, E. Time to cracking for chloride-induced corrosion in reinforced concrete. Corros. Reinf. Concr. Constr. R. Soc. Chem. Lond. 1996, 183, 88-104.

11. Funahashi, M. Predicting corrosion-free service life of a concrete structure. ACI Mater. J. 1990, 87, M62.

12. Clear, K.C. Time-to-Corrosion of Reinforcing Steel in Concrete Slabs. Volume 3: Performance after 830 Daily Salt Applications; The National Academies of Sciences, Engineering, and Medicine: Washington, DC, USA, 1976.

13. West, R.E.; Hime, W.G. Chloride profiles in salty concrete. Mater. Perform. 1985, 24, $29-36$.

14. Tritthart, J. Chloride binding in cement II. The influence of the hydroxide concentration in the pore solution of hardened cement paste on chloride binding. Cem. Concr. Res. 1989, 19, 683-691. [CrossRef]

15. Yu, H.; Chiang, K.-T.K.; Yang, L. Threshold chloride level and characteristics of reinforcement corrosion initiation in simulated concrete pore solutions. Constr. Build. Mater. 2012, 26, 723-729. [CrossRef]

16. Jiang, L.; $\mathrm{Xu}, \mathrm{J}$; $\mathrm{Zhu}, \mathrm{Y}$.; Mo, L. Influence of chloride salt type on threshold level of reinforcement corrosion in simulated concrete pore solutions. Constr. Build. Mater. 2012, 30, 516-521. [CrossRef]

17. Xu, J.-x.; Jiang, L.-h.; Wang, W.-l.; Tang, L.; Cui, L. Effectiveness of inhibitors in increasing chloride threshold value for steel corrosion. Water Sci. Eng. 2013, 6, 354-363. 
18. Cabrini, M.; Fontana, F.; Lorenzi, S.; Pastore, T.; Pellegrini, S. Effect of organic inhibitors on chloride corrosion of steel rebars in alkaline pore solution. J. Chem. 2015, 2015, 521507. [CrossRef]

19. Liu, Y.; Song, Z.; Wang, W.; Jiang, L.; Zhang, Y.; Guo, M.; Song, F.; Xu, N. Effect of ginger extract as green inhibitor on chloride-induced corrosion of carbon steel in simulated concrete pore solutions. J. Clean. Prod. 2019, 214, 298-307. [CrossRef]

20. Hassoune, M.; Bezzar, A.; Sail, L.; Ghomari, F. Chloride threshold value to initiate steel corrosion in simulated concrete pore solution, and the effectiveness of DMEA as an amino-alcohol-based corrosion inhibitor. J. Adhes. Sci. Technol. 2020, 35, 504-521. [CrossRef]

21. Nahali, H.; Dhouibi, L.; Idrissi, H. Effect of phosphate based inhibitor on the threshold chloride to initiate steel corrosion in saturated hydroxide solution. Constr. Build. Mater. 2014, 50, 87-94. [CrossRef]

22. Uwah, I.; Okafor, P.; Ebiekpe, V. Inhibitive action of ethanol extracts from Nauclea latifolia on the corrosion of mild steel in $\mathrm{H}_{2} \mathrm{SO}_{4}$ solutions and their adsorption characteristics. Arab. J. Chem. 2013, 6, 285-293. [CrossRef]

23. Singh, M.R.; Gupta, P.; Gupta, K. The litchi (Litchi Chinensis) peels extract as a potential green inhibitor in prevention of corrosion of mild steel in $0.5 \mathrm{M} \mathrm{H}_{2} \mathrm{SO}_{4}$ solution. Arab. J. Chem. 2019, 12, 1035-1041. [CrossRef]

24. M'hiri, N.; Ioannou, I.; Ghoul, M.; Mihoubi Boudhrioua, N. Phytochemical characteristics of citrus peel and effect of conventional and nonconventional processing on phenolic compounds: A review. Food Rev. Int. 2017, 33, 587-619. [CrossRef]

25. Mammoliti, L.; Hansson, C.; Hope, B. Corrosion inhibitors in concrete Part II: Effect on chloride threshold values for corrosion of steel in synthetic pore solutions. Cem. Concr. Res. 1999, 29, 1583-1589. [CrossRef]

26. Ormellese, M.; Bolzoni, F.; Lazzari, L.; Pedeferri, P. Effect of corrosion inhibitors on the initiation of chloride-induced corrosion on reinforced concrete structures. Mater. Corros. 2008, 59, 98-106. [CrossRef]

27. Singh, J.K.; Yang, H.-M.; Lee, H.-S.; Mandal, S.; ASLAM, F.; Alyousef, R. Role of L-arginine on the formation and breakdown of passive film onto the steel rebars surface in chloride contaminated concrete pore solution. J. Mol. Liq. 2021, 337, 116454. [CrossRef]

28. Lee, H.-S.; Yang, H.-M.; Singh, J.K.; Prasad, S.K.; Yoo, B. Corrosion mitigation of steel rebars in chloride contaminated concrete pore solution using inhibitor: An electrochemical investigation. Constr. Build. Mater. 2018, 173, 443-451. [CrossRef]

29. Mandal, S.; Singh, J.K.; Lee, D.-E.; Park, T. Effect of phosphate-based inhibitor on corrosion kinetics and mechanism for formation of passive film onto the steel rebar in chloride-containing pore solution. Materials 2020, 13, 3642. [CrossRef]

30. Mandal, S.; Singh, J.K.; Lee, D.-E.; Park, T. Ammonium phosphate as inhibitor to mitigate the corrosion of steel rebar in chloride contaminated concrete pore solution. Molecules 2020, 25, 3785. [CrossRef] [PubMed]

31. Singh, D.; Ghosh, R. Corrosion resistance performance of fusion bonded epoxy coated rebars used as reinforcement in concrete structures. J. Metall. Mater. Sci. 2003, 45, 73-83.

32. Ghosh, R.; Singh, D. Kinetics, mechanism and characterisation of passive film formed on hot dip galvanized coating exposed in simulated concrete pore solution. Surf. Coat. Technol. 2007, 201, 7346-7359. [CrossRef]

33. Yang, H.-M.; Myung, N.V.; Lee, H.-S.; Singh, J.K. L-arginine-incorporated cement mortar as sustainable artificial reefs. Sustainability 2020, 12, 6346. [CrossRef]

34. Badawy, W.A.; Ismail, K.M.; Fathi, A.M. Effect of Ni content on the corrosion behavior of Cu-Ni alloys in neutral chloride solutions. Electrochim. Acta 2005, 50, 3603-3608. [CrossRef]

35. Figueira, R.B.; Sadovski, A.; Melo, A.P.; Pereira, E.V. Chloride threshold value to initiate reinforcement corrosion in simulated concrete pore solutions: The influence of surface finishing and pH. Constr. Build. Mater. 2017, 141, 183-200. [CrossRef]

36. Li, L.; Sagues, A. Chloride corrosion threshold of reinforcing steel in alkaline solutions-Open-circuit immersion tests. Corrosion 2001, 57, 19-28. [CrossRef]

37. Jiang, L.; Liu, H.; Chu, H.; Zhu, C.; Xiong, C.; You, L.; Xu, J.; Zhang, Y.; Qin, Y. Influence of compression fatigue on chloride threshold value for the corrosion of steels in simulated concrete pore. Constr. Build. Mater. 2014, 73, 699-704. [CrossRef]

38. Kim, K.; Chang, H.; Lim, B.; Park, H.; Kim, Y. Effect of ethanolamines on corrosion inhibition of ductile cast Iron in nitrite containing solutions. Corros. Sci. Technol. 2016, 15, 171-181. [CrossRef]

39. Singh, M.R.; Bhrara, K.; Singh, G. The inhibitory effect of diethanolamine on corrosion of mild steel in $0.5 \mathrm{M}$ sulphuric acidic medium. Port Electrochim. Acta 2008, 26, 479-492. [CrossRef]

40. Garcia-Arriaga, V.; Alvarez-Ramirez, J.; Amaya, M.; Sosa, E. $\mathrm{H}_{2} \mathrm{~S}$ and $\mathrm{O}_{2}$ influence on the corrosion of carbon steel immersed in a solution containing $3 \mathrm{M}$ diethanolamine. Corros. Sci. 2010, 52, 2268-2279. [CrossRef]

41. Ryu, H.-S.; Singh, J.K.; Lee, H.-S.; Ismail, M.A.; Park, W.-J. Effect of $\mathrm{LiNO}_{2}$ inhibitor on corrosion characteristics of steel rebar in saturated $\mathrm{Ca}(\mathrm{OH})_{2}$ solution containing NaCl: An electrochemical study. Constr. Build. Mater. 2017, 133, 387-396. [CrossRef]

42. Ryu, H.-S.; Singh, J.K.; Lee, H.-S.; Park, W.-J. An electrochemical study to evaluate the effect of calcium nitrite inhibitor to mitigate the corrosion of reinforcement in sodium chloride contaminated $\mathrm{Ca}(\mathrm{OH})_{2}$ solution. Adv. Mater. Sci. Eng. 2017, $2017,6265184$. [CrossRef]

43. Yohai, L.; Vázquez, M.; Valcarce, M. Phosphate ions as corrosion inhibitors for reinforcement steel in chloride-rich environments. Electrochim. Acta 2013, 102, 88-96. [CrossRef]

44. Shi, J.-j.; Sun, W. Electrochemical and analytical characterization of three corrosion inhibitors of steel in simulated concrete pore solutions. Int. J. Miner. Metall. Mater. 2012, 19, 38-47. [CrossRef]

45. Monticelli, C.; Frignani, A.; Balbo, A.; Zucchi, F. Influence of two specific inhibitors on steel corrosion in a synthetic solution simulating a carbonated concrete with chlorides. Mater. Corros. 2011, 62, 178-186. [CrossRef] 
46. Yohai, L.; Schreiner, W.; Valcarce, M.B.; Vázquez, M. Inhibiting steel corrosion in simulated concrete with low phosphate to chloride ratios. J. Electrochem. Soc. 2016, 163, C729. [CrossRef]

47. Orazem, M.E.; Pébère, N.; Tribollet, B. Enhanced graphical representation of electrochemical impedance data. J. Electrochem. Soc. 2006, 153, B129. [CrossRef]

48. Brug, G.; van den Eeden, A.L.; Sluyters-Rehbach, M.; Sluyters, J.H. The analysis of electrode impedances complicated by the presence of a constant phase element. J. Electroanal. Chem. Interfacial Electrochem. 1984, 176, 275-295. [CrossRef]

49. Huang, V.M.-W.; Vivier, V.; Orazem, M.E.; Pébère, N.; Tribollet, B. The apparent constant-phase-element behavior of a disk electrode with faradaic reactions: A global and local impedance analysis. J. Electrochem. Soc. 2006, 154, C99. [CrossRef]

50. Hirschorn, B.; Orazem, M.E.; Tribollet, B.; Vivier, V.; Frateur, I.; Musiani, M. Determination of effective capacitance and film thickness from constant-phase-element parameters. Electrochim. Acta 2010, 55, 6218-6227. [CrossRef]

51. Macdonald, D.D.; Ismail, K.M.; Sikora, E. Characterization of the passive state on zinc. J. Electrochem. Soc. 1998, $145,3141$. [CrossRef]

52. Al-Negheimish, A.; Alhozaimy, A.; Hussain, R.R.; Al-Zaid, R.; Singh, J.; Singh, D. Role of manganese sulfide inclusions in steel rebar in the formation and breakdown of passive films in concrete pore solutions. Corrosion 2014, 70, 74-86. [CrossRef]

53. ASTM International West. ASTM G102. Standard Practice for Calculation of Corrosion Rates and Related Information from Electrochemical Measurements; ASTM International West: Conshohocken, PA, USA, 2010. 